\title{
Numerical Simulations of In-Situ Neutron Detector Calibration Experiments on the Tokamak Fusion Test Reactor
}

\author{
L. P. Ku, H. W. Hendel, S. L. Liew, and J. D. Strachan \\ Princeton Plasma Physics Laboratory \\ Princeton, NJ 08543-0451
}

\begin{abstract}
Accurate deterninations of fusion neutron yields on the TFTR require $t$ at the neutron delectors be absolutely calibrated in-gitu, using neutron sources of nown strengths. For such calibrations, numerical simulations of neutron transport can be powerful tools in the design of experiments and the study of measurement results. Un the TF'PR, 'numerical calibration experiments' have been frequently used to complement actual detector calibrations. We present calculational approaches and transport models used in these numerical simulations, and summarize the results from simulating the calibration of ${ }^{235} \mathrm{U}$ fission detectors carried out in December 1988.
\end{abstract}

\section{DISCLAIMER}

\begin{abstract}
This report was prepared as an account of work sponsored by an agency of the United States Government. Neither the United Slates Government nor any agency thereof, nor any of their employees, makes any warranty, express or implied, of assumes any legal liability or responsibility for the accuracy, completeness, or usefulaess of any information, apparatus, product, or process disclosed, or represents that its use would not infringe privately owned rights. Reference herein to any specific commercial product. process, or service by trade name, trademark, manufacturer, or otherwise does not necessarily constitute or imply its endorsement, recommendation, of favoring by the United States Government or any agency thereoi. The views and cpinions of authors expressed herein do nol necessarily state or seflect those of the United Slates Government or any agency thereor.
\end{abstract}




\section{Introduction}

The Tokamak Fusion Test Reactor (TFTR), designed to study the physics of renctorlike plasmas near power breakeven, now routinely produces neutrons in excess of $10^{16}$ per second. ${ }^{1}$ Measurement of the total neutron production yields the fusion power gain factor $Q$ (fusion power/input power), i.e., a direct measure of the fusion power production of the plasmas. The main diagnostic on the TFTR for measuring the fusion neytrons is a set of seven fission detectors. ${ }^{2}$ Fission detectors, in particular thuse of the ${ }^{235} \mathrm{U}$ type surrounded by a moderator, offer last response, good $\gamma$-ray discrimination, and ligh efficjency. Since the detectors can only measure the neutron flux al the detector locations, absolute detector efficiencies, in terms of counts per source neutron, have to be determined in order to. relate the flux at the delector lucation to the total neutron source strength of the plasme. On the TFTR, the detertion efficiencies are derived from in-situ measurements, using point sources of known strengths to simulate the toroidal plasma. ${ }^{3}$

Ideally, one should choose a calihration source having the same energy, angular, and spatial distributions as those of the plasma source. Since sucli a source does not exist, some approxinuations of the source conditions must be made. The effect of sonrce spatial extent can be taken into account by integrating the point calibration eflicjencies. Neutron genterators can be used to obtain the desired DD or DT neutron spectrinm. Ilowever, the perturbations introduced by the massive generator, the dificulties in oblaining accurate neutron yields, and the problems of maneuvering the generator in the linniled space of the tokamak vacuum vessel, often render the generalor misnitable. Using spontaneous fission or $(\alpha, n)$ sources are possible alterratives, but their energy spectra may not be quite the same as those from DD or D'l fusion. Further, the calibration sources typically are not intense enough, so that only the nost sensitive detectors can be calibrated in-situ directly; other detectors can only be cross-calibrated with a plasma neutron source in appropriate ranges. On Whe 'TFT'R, the ${ }^{235} \mathrm{U}$ detectors in cou $2 \mathrm{t}$ rate mode are the only ones which can be adeguately (with good statistics) calibrated in-situ. The Campbell and current modes of the ${ }^{235} \mathrm{U}$ detectors, as well as all o her less sensitive neutron detectors, including the activation foils and ${ }^{238} \mathrm{U}$ detectors, would have to be cross-calibrated, using the more intense plasma neutron source.

Many of the problems encountered in the in-situ calibration, particularly those concerning the design of experiments and the interpretation of results, can be studied by numerical simulations using neutron transport codes. On the TFTR, numerical calibration experiments have been conducted frequently. To be able to simulate experiments, we need reliable and flexible neutron transport models of the TFTR. For a compiex rlevice like TFTR it is very dificult to include all the geometrical details in 
the transport calculations. In addition, neutrons may suffer many collisions near the tokamak with many auxiliary machine components, yet they may still make significant contributions to the delector response, and our detectors have been designed to detect these inulti-scattered neutrong with nearly energy-independent detection efliciency to recuce variations of detection efficiency for changes in plasma location and size. It is possible to perform senvitivity analysis to see the calculational uncertainties due to the imperfect modeling, but it is quite difficult to include all possible situations. Thus, it is not fessible to determine directly the alssolute detection efficiency to an acceptable accuracy $(<10 \%$ ), with neutron transport calculations alone, without normalizing the results to some measurements on the TFTR. To provide a practical 8pproach lor simulating varions experiments which involve only tlie ${ }^{235} \mathrm{U}$ detectors, and to avoid the difficulties in describing the detailed geometries, we have developed sinulation models for the TF'R which contain two adjustable parameters (region density factorn). The parameters were determnined by matching the results of calculation for one of the ${ }^{235} \mathrm{U}$ fissiun detectors (NE-1, Neutron Epithermal) with a small set of measurements. The detailed procedures of this approach can be found in Ref. 1. This 'semi-empirical' model was then used to simulate calibration experiments and to calculale detector responses for dilferent source and source-detector georne-

tries. Results obtained using this approacl generally agree well with the available measured data over a wide range of energies, geonetries, and detector sensitivities.

In this paper, we review our calculational approaclies and transport models, and discuss the results of simulations for the in-silu calibration experiment carried out on the TFTR in December 1988. We show examples of using neutron transport simulations to in vestigate possilule systematic errors in the calibration experiments; to stuly, by varying the conditions in numerical experiments, the peculiarities oiserved in the in-situ calibration; to calculate detector efficiencies for sources in energy-s pace regions not accessible in real experiments; and to derive differential information useful for the understanding of neutron transport in the TFTR.

\section{The TFTR Fission Detector System}

A list of fission detectors currently operational on the TFTR is given in Table 1, along wilh their applicable source strength ranges. Of these detectors, only NE-1, NE-2, aud NE-6 can be calibrated using a manually handled calibration source inside the tokanak racuum vessel. NE-1 and NE-2 will be our anain focus of discussiou, since NE-6 was not included in the calibration experinent.

NE- 1 and NE-2 are fission cointers of the Reuter-Stokes type RS-C3-2510-114 whiclı corstain $1.3 \mathrm{~g}$ of ${ }^{295} \mathrm{U}$ distributed over a cylindrical area $7 \mathrm{~cm}$ in diameter and 
$23.5 \mathrm{~cm}$ in length. They have a useful dynamic range of $10^{3}$ to $5 \cdot 10^{5}$ counts per second (c.ps) in the connt rate mode, and $10^{5}$ to $10^{9}$ equivalent cps in the current and Camplell modes, using Gamma-Metrics electrouics. ${ }^{5}$ Each detector is surrounded by an clectrostatic shield of $0.35 \mathrm{~cm}$ in thickness, and a moderator/shield made of polyethylene and lead, $5.05 \mathrm{~cm}$ and $9.95 \mathrm{~cm}$ in thickness, respectively. The outer surface is covered with a borou partel.

NE-1 is localed in bay $\mathbf{C}$ on the machine substructure behind the lower shear compression pauel, appresimately $5.6 \mathrm{~m}$ from the machine center and $1.75 \mathrm{~m}$ below milplaue. One of the two TFTR vacuum pumping ducts is located right above the detcctor. The shear compression panel has an equivalent steel thickness of $25 \mathrm{~cm}$. Together with the toroidal field coils, the shear panel nearly completely blocks off the direct neutron passage from the torus, so that virtually no uncollided neutrons reach the detcctor assembly. NE-2 is localed in bay $\mathrm{M}$, with almost the same detector gcomrtry and clectronics. The ion cyclotion resonance heating antenna is mounted on the bay $M$ port, with transmission lines lucated above the delector. The local conponent layout is even more complex.

A typical signal trace of NE-2 for a neutral deuterium beam-lieated deuterium plasma is illustraled in Fig. 1.

\section{Numerical Algorithms and Simulation Models}

\section{A. Monte Carlo simulations of neutron transport}

We wish to set up a calculational model that enables us to per[orm numerical experiments as close to the real experiments as possible, and also flexible enough to allow the study of various parametric variations. The complex toroidal geometry of the 'IF"l'll, with nonuniformly and asymmetrically distributed mactine components, means that a full three-dimensional representation of the TFTR would be required in the numerical model if the experiments using a point source, which can be located anywhere inside the vacuum vessel, can be simulated. To solve the neutron transport equation in such a complex three-dimensional geometry, the Monie Carlo technique is the only practical method available.

ETicient calculations using Monte Carlo methods, however, cannot be achieved by following particle histories directly until enough counts are registered in the detector, since the detector/moderator assembiy is rery small compared to the tokamak. To improve the cfficiency of the numerical simulation, we have developed a coupling 
algorithm, the details of which have been presented in Ref. 4. The basic idea was to detcrmine the surface efficiency $\epsilon$, for the detector/moderator assembly, and to substitute the Monte Carlo scoring function $\mathcal{R}$ with $\epsilon_{\text {. }}$. The pseudo-collision (or so-called last flight estimator) method can then be used in which the probability of contributing to the detector score is estimated at every collision site to obtain the overall detector response of interest. A neutron is no longer required to enter the detector to register a count. It was shown that $\epsilon$, could be represented by the adjoint function on the surface of the moderator and detector assembly and could be derived independently of the neution transport in the TFTR. The relative surface respouse coelficients are illustrated in Fig. 2. We note that the response function is remarkalsly insensitive to the energies of the neutrons incident on the moderator in the $\mathrm{keV}$ and $\mathrm{MeV}$ range.

\section{B. Details of the simulation model}

The tool used to perform transport simulations is the MCNP Monte Carlo corle, version 3B. 'The RMCCS nuclear data set, primarily based on the ENDF/B-V evaluntions, ${ }^{7}$ was used in the transport calculations. The neutron spectrum from ${ }^{252} \mathrm{Cf}$ sponlaneous fission was taken from an NBS cvaluation, and is illustrated in Fig. 3. Various biasing schenres were used to speed up the calculations, such as particle track splitting and Russian Roulette, implicit capture, energy and weight cutofls, cell importance, and Russian Rouletle on detector tallies.

In our inodels, the TFTR components are described by $\sim 300$ surfaces, and these surfaces are combined into the specifications of $\sim 300$ colls. The geometrical descriptions common to all the detectors include the vacuum vessel with homogenized representation of the port covers, lellows cover plates, inuer bumper limiter, outer carbon tiles, polvidal field and toroidal field coils, the center column assembly, shear compression panels, floor and buileling walls. The upper umbrella structure, column support structure, auxiliary machitue components (such as cable trays, cooling water lines, N13L drift tubes, etc.) and diagnostics which are not in the bay of interest are rcpresented as two homogenized malerial zones. The region between the vacuum vessel and 'TF coils is filled with SS-304 of 5\% density factor; the region outside the TF but inside the pedestal $(R=6.5 \mathrm{~m})$ is filled witl SS-304 of $20 \%$ density factor plus $2 \%$ of water equivalent hydrogen. These pseudo-materials were chosen by parantetrically varying the density factors and comparing with the results from previons ${ }^{235} \mathrm{U}$ calibration experiments to find the best match for a small set of data for NE-1. The geometries of bays $\mathrm{C}$ and $\mathrm{M}$, where the two ${ }^{235} \mathrm{U}$ fissions detectors are located, are nodeled in as much detail as possible. Tlie major features modeled in Bay $\mathrm{C}$ include the support columns filled with grout and the torus vacuum pumping duct. 
In Bay $M$, the wave transmission lines, antenna, and limiters for the ion cyclotron resonance lieating are modeled. A few plots of the models are given in Fig. 4.

\section{Simulations of Fission Detector Calibrations with ${ }^{252} \mathrm{Cf}$ Source}

For a print calibration source, the fission detector response varies as a function of the energy and angle of emission of the source neutrons, as well as the location (tlie major radius, height, and toroidal angle) of the source. In the 1988 calibration experinent, only a ${ }^{252} \mathrm{CI}$ spontaneous fission source was used. For all practical purposes, Cf is an isotropic point source. An atlempt was made to modify the angular distribution of the newtron emission to study the effects of angular anisotropy on the detector response. Whe delector response to a volumetric source was obtained hy numerically integrating the measured discrete data points. The prinary variables of the neutron source in the in-situ calibration are then the positions of the ${ }^{252} \mathrm{Cr}$. A typical calibration result is shown in Fig. 5.

\section{A. Comparisons with measurements}

Cumparisons of results for detectors NE-1 (in bay $C$ ) and NE-2 (in bay $M$ ) are given is 'lable 2. The comparisons slown are for sources located at a majur radius of $2.65 \mathrm{~m}$ and at the torus midplane. Both NE-1 and NE-2 are surrounded by similar polyethylene moderators and $\mathrm{P} b$ shields, and both have the same geometry, electronic selup, and response characteristics. In the experimental setup, the ${ }^{252} \mathrm{Cf}$ was supported by a Plexiglas liolder. The holder itself was in turn supported by two toroidal rails. During the calibration, the effect of the acrylic source support on the count rate liacl been determined lyy removing it during a part of the experiment. In the numerical simulations, the effect of the source holder on the detection efficiency was studied by comparing the results with and without the holder being modelled for the source at toroidal angle $\phi=0^{\circ}$ (the angle with respect to the toroidal location of the detector). Otherwise, the acrylic source holder was not included in the calculations. The uncertainties in the calculated resalis given in Table 2 are one standard errors due only to the statistics in the Monte Carlo sampling. The nncertainties in the measured results are one standard errors due only to the counting statistics. Must of the quoted experimental results are the equal-weight averages of a few measurements in the vicinity of the reference toroidal angle (within $\pm 3^{\circ}$ ).

It is seen that measurements and calculations agree reasonably well ( $\pm 5 \%$ ). The 
calculations were able to reproduce the correct gradient of the efficiency curve as a function of toroidal angles, and the changes in efficiency due to the difference in bay geometry. The results seemed to indicale that the acrylic tube holding the ${ }^{252} \mathrm{Cf}$ may cause a small reduction in the detection efficiency (perhaps $2-5 \%$ ). This reduction in detection efficiency may be attributed to the softening of the calculated energy spectrum for neutrons interacting with the acrylic holder. Comparison of the energy spectrum of the neutrons leaving the acrylic tube with that of the ${ }^{262} \mathrm{Cf}$ shows that the mean energy is reduced by $\sim 5 \%$. Perhaps more important is that the number of neutrons with energies above $500 \mathrm{keV}$ has also been reduced by $\sim 5 \%$, depending upon the polar and azimuthal angles of emission. These neutrons have been identified to make most contribntions to the delector response (see Section VI). Nevertheless, since the statistical error in the Monte Carlo calculation for the elliciency ratios is $\sim 4 \%$, we cannot confidently tell the magnitude of reduction in the letection elliciency. This conclusion is consistent with the observation made during the calibratiost experiment. ${ }^{3}$

\section{B. Simulations for two special experiments}

1. Simulntion of the experiment for the study of the effect of source-
detector distance at $v^{\circ}$ toroidal angle

During the 1988 calibration experiment, it was suggested that it might be useful to study the effect of the distauce between the source and detector on the detection efficiency. The ${ }^{252} \mathrm{Cf}$ source was moved along the line-of-sight between $\mathrm{NE}-2$ and the position $\phi=0^{\circ}, R=2.65 \mathrm{~m}$ and $\mathrm{Z}=0 \mathrm{~m}$. It was observed that (at $\phi=0^{\circ}$ ) the measured delector efficiency approximately varies as the inverse of the distance squared (the distance from the source to the detector). ${ }^{3}$ Since the detector was localed behind the shear compression panels with a total steel thickness of $\sim 30 \mathrm{~cm}$ between the telector atul source (hence, the uncollided neutrons make negligible contributions to the detector response), this distance dependence seems unexpected. However, since the density of the TF coils is much higher than that of the materials in the bay region, the two adjacent TF coils serve as effective collimators, and thus, the above observed distance dependence would follow.

Table 3 shows the results of the simulation, with the correct TF geometry as well as with the TF region replaced by the $5 \%$ density SS-304 used in the first homogenized material zone. The responses calculated with the correct TF geometry compare well with the measurements. We observe that with the TF present, the efliciency is approximately proportional to the inverse of the distance squared, as observed in the experiment, but this correlation to longer loolds when the TF coils 
are removed. Without the TF coils, the distance dependence is more like $l^{-1}$, where $l$ is the distance from the source to the detector.

\section{Simulation of the experiment for the study of the effects of emission anisstropy}

For a beam-heated DD plasma, the neutron emission is not isotropic in the laboratory syoten. Effects on detector calibration due to the non-isotropic emission of n neutron generator calibretion source have been discussed briefly before. ${ }^{0}$ To study in detail experimentally the effects of auisotropy in the neutron emission on the delection efficiency for the fission detectors, it was proposed, initially, to place small shickls made of polyethylene or steel arount the ${ }^{232}$ Cf to alter the angle of emission for neutrons leaving the source assembly. While using a shadow shield would achieve the objective of having a biased emission angular distribution, the entergy spectrum of the ncutrons leaving the shield would be inevitably degraded. 'The objective of this numerical study is to examine the feasibility of performing in-situ calibration using this approach.

'Tlie polyetlyylene shield dletermined to be suitable consists of a cylindrical sliell which has a central bore radius of $1.75 \mathrm{~cm}$ and a shell thickness of $3.65 \mathrm{~cm}$. The axial length of the slield is $6.03 \mathrm{~cm}$. The corresponding dimensions for the steel slield are $1.27,5.08$, and $6.67 \mathrm{~cm}$, respectively. The calculated polar angle distribution relative to the axis of the cylinders is shown in Fig. 6, along with a distrib ation corresponding to that of the $120-\mathrm{keV}$ deuterium beam interacting with a stationary deuterium target. As expected, the cylindrical shields result in more neutrons being emitted in the forward and backward $30^{\circ}$ angles, and less neutrons in the perpendicular direction, compared to the DD emission profile. Despite these diflerences, the source sliclds do provicle angular variations for the geutrons similar to the emission profile desired for the study. 1'he energy distribution at the $90^{\circ}$ emission angle (azimuthally averagel) is given in Table 4 . It is seen that the energy spectra of the neutrons emilted Irom both shields are much softer, with a reduction of $3.1 \%$ and $20 \%$ in the mean energy for the polyethylene and steel shields, respectively. The number of neutrons born with energies abuve $500 \mathrm{keV}$ is also reduced from $90 \%$ for a bare ${ }^{252} \mathrm{Cf}$ to $66 \%$ for the ${ }^{252} \mathrm{Cf}$ wilh polyellyylene shield, and to $81 \%$ for the ${ }^{252} \mathrm{Cf}$ with SS-316 shield.

Talıle 5 provides a summary of the results rbtained from a series of transport simulations. The source was assumed to be located at a major radius of $2.65 \mathrm{~m}$, and the axis of the shield cylinder was assumed to be tangential to the vessel minor axis. The DD neutron angular distribution used in the table refers to that expected from 
a $120 \mathrm{keV}$ deuterium beam interacting with a stationary deuterium target. ${ }^{10}$

We note that with the polyethylene shadow shield, the efficiency of NE-2 at the $0^{\circ}$ toroidal angle is reduced by nearly $40 \%$, and with the SS-316 slield by $20 \%$. Of these reductions, about $15 \%$ is attributable to the bias in source angle; the remainder is due to the degradation in energy resulting from neutron collisions with the source shield. It is interesting to note that, when the angular emission profile for the DD neutrons was used while keeping the energy spectrum of ${ }^{262} \mathrm{Cf}$ unchanged, the efficiency at $\phi=0^{\circ}$ is reduced by ahout $10 \%$. This reduction reflects the fact that a smaller-tlinti-average number of neutrons would be emitled in the radial direction for the biased source (the direction tonard the detector), and clearly indicates that there in a preferred initial direction, albeit a relatively weak one, for those neutrons contributing to the detector response.

At toroidal source locations $\phi=30^{\circ}$, the detection efficiency is higher for the angularly hiased source (with the energy spectrum unchanged), resulting from the ligher-than-average number of neulrons emitted in the direction toward the detecior. Similar to the $\phi=0^{\circ}$ case, the degradation in neutron energy due to the presence of the source shield has significant effects on the detectiont efficiency. The inability lo separale the elfect of angular anisotropy from the effect resulting from the energy regraclation in the experimental results inakes it difficult to determine quantitatively the nagnitude of cliange in the absolute detection efficiency that is attributable to the anisotrony in the $\mathrm{DD}$ nentron emission. We note that, whereas there is a clear dependence of the detection efficiency on the profile of neutron angular emission for a point source. the angular effect will be averaged out for a toroidal source, as evidenced in the following section.

\section{Derivation of ${ }^{235} \mathrm{U}$ Detector Efficiency for DD Neutrons by Numerical Simulations}

As mentioned above, the detector efficiency is a function of the neutron sonrce energy, position, and angular emission. For a plasma neutron source, the major source variables are the major and minor radii, energy distribution, and the angle of cmission. The expcrimental evidence, ${ }^{3}$ together with previous transport calculations, indicated that the detectors are insensitive to the source minor radius. Thus, we concentrated on the stindy of the effects of source neutron energy, angle of emission, and source major radius. In particular, since the in-situ calibration carried out in 1988 was done only with a ${ }^{252} \mathrm{Cf}$ sonrce, one of the major goals of our numerical study is to derive detection efficiencies for $\mathrm{DD}$ neutrons. 
The ${ }^{235} \mathrm{U}$ detector efficiencies for both the $\mathrm{DD}$ thermonuclear fusion and beamheated plasma at a fixed beam energy and direction have been studied. Table 6 suminarizes the results ior ring sources, all with a major radius of $2.65 \mathrm{~m}$. In the case of thermonuclear fusion, we have assumed that the spectrum of neutron emission folluws the typical Gaussian furm and the emission angle is isotropic in the laboratory system. In the beam-plasma case, we have assumed that a beam of monoenergetic ions of $120 \mathrm{keV}$ circulates along the major radius at $2.65 \mathrm{~m}$ unidirectionally, and interacts with a 'culd' target witlt negligible thermal velocity. The angular distribution of neutrons was taken from the compilation of hiskien and Paulsen, ${ }^{10}$ and the energy distribution of the neutrons was calculated from the interaction kinematics.

The results sliow that there is a $5-7 \%$ variation in the detection efficiency for various source conditions, but the diferences are not statigtically siguificant because the magnitude of the differences is comparable to $1 \sigma$ of the Monte Carlo calculations. We note that the effect of angular anisotropy in the neutron emission given above represents the extreme case. In a real tokanak operation with energetic denterium injerted into a background deuterium plasma, the effect will be mitigated by the slowing down and pitch angle scattering of the fast ions, the randomization of the reference direction of neutron entission due to the presence of $v_{1}$, and the presence of a thermonuclear reaction component in addition to the beam-driven components. The derived ralio of $\mathrm{DD}$ to ${ }^{252} \mathrm{Cf}$ detection efficiency at $\mathrm{R}=2.65 \mathrm{~m}$ is $1.1 \pm 7 \%$ for NE-1, and is $1.08 \pm 7 \%$ for NE-2.

The dependence of NE-1 on the major radius of a plasma ring source is shown in Fig. 7 for $2.05 \mathrm{~m} \leq \mathrm{R} \leq 3.25 \mathrm{~m}$. The lineat least square fit gives an efficiency change per unit chlange in major radius, $\delta \epsilon / \delta \Omega=(5.58 \pm 1.86) \cdot 10^{-10}$ counts $/$ source $/$ meter, or equivalently, $\delta \epsilon / \epsilon / \delta R=(0.15 \pm 0.05) \% / \mathrm{cm}$. The dependence on source major radius for NE-2 is expected to be similar. The measured value of $\delta \epsilon / \epsilon / \delta R$ for NE-2 usitg a ${ }^{252} \mathrm{Cf}$ source was $0.4 \%$ for $\mathrm{R}<2.65 \mathrm{~m}$, and $\sim 0.1 \%$ for $\mathrm{R}>2.65 \mathrm{~m}^{3}$

\section{Neutron Transport Studies of the Importance of the Energy Spectrum, and the Spatial and Angular Emis- sion of Source Neutrons for the ${ }^{235} U$ Detectors}

The above discussions evidently show that there are regions in phase space in which thettrons, either born there or having scatterings, would have higher probability in contributien to the detector. We have carried out further transport calculations to idlentify the relative importance of the neutron initial spa:jal location, energy, and emission angle for NE-2. The upper energy boundary in this study was extended to 
include the DT fusion neutrons. For the spatial variable, we have fixed the major radius at $2.65 \mathrm{~m}$, and investigated the relative importance of the source toroidal location relative to the detector.

We define the importance of the source neutrons, $I(E, \phi, \eta)$, as

$$
\epsilon=\int_{0}^{\infty} \int_{0}^{2 \pi} \int_{-1}^{1} I(E, \phi, \eta) \cdot S(E, \phi, \eta) d E d \phi d \eta
$$

where $\epsilon$ is the NE-2 detection efficiency, $S(E, \phi, \eta)$ is the source strength per unit energy, toroidal angle $(\phi)$, and the cosise of the polar angle of emission $(\eta)$. The reference direction for the polar angle : neutron emission at $\phi$ is taken to be the vector tangent to the circie of radius $2.65 \mathrm{~m}$ at $\phi$ and pointing loward the detector. We further define

$$
I_{i}(E, \phi)=\int_{-1}^{1} I(E, \phi, \eta) d \eta
$$

autl

$$
I_{a}(E, \phi, \eta)=\frac{I(E, \phi, \eta)}{I_{i}(E, \phi)} .
$$

Equation ( 1 ) can be Ie-written as

$$
\epsilon=\int_{0}^{\infty} \int_{0}^{2 \pi} \int_{-1}^{1} I_{a}(E, \phi, \eta) I_{i}(E, \phi) S(E, \phi . \eta) d E d \phi d \eta
$$

The source is usually assumed uniform in $\phi$,

$$
\epsilon=\int_{0}^{\infty} \int_{0}^{2 \pi} \int_{-1}^{1} J_{a}(E, \phi, \eta) I_{i}(E, \phi) \frac{S(E, \eta)}{2 \pi} d E d \phi d \eta
$$

We note that $I_{\mathrm{i}}(E, \phi)$ is the response of the detector for an isotropic source with energy $E$ and at toroitlal angle $\phi$. Figure 8 shows $I_{i}(E, \phi)$ for $\phi=0,30,60,90,120$, 150 , and 180 degrees, in arbitrary units, obtained from a multi-group adjoint MCNP calculation. Characteristic to all the curves is that the source-energy importance changes little above $1 \mathrm{MeV}(\sim \pm 15 \%)$, but decreases rapidly below $500 \mathrm{keV}$. Thus, any collision of source neutrons with materials surrounding the source which results in an energy below a few hundred $\mathrm{keV}$ is virtually equivaleri to an absorption reaction insofar as the ${ }^{235} \mathrm{U}$ detection efficiency is concerned. The insensitivity of the importauce function to the source energy in the MeV region, which has been confirued experimentally, ${ }^{11}$ is the basis for using ${ }^{252} \mathrm{Cf}$ as the sole calibration source iu 1988. From Fig. 8 we also see that the efficiency of NE-2 is $\sim 14 \%$ higher for a D'T source than for a $\mathrm{DD}$ source.

Figure 8 also shows the decrease of source neutron importance as a function of the source toroidal angle. The slope of the toroidal angle dependence follows closely to 
that obtained from the calibration experiment. The importance of source neutrons witl ettergies greater than $1 \mathrm{MeV}$ is decreased by $\sim 2$ at a toroidal angle of $30^{\circ}$, by $\sim 5$ at $60^{\circ}$, by $\sim 10$ at $90^{\circ}$, and by $\sim 100$ at $180^{\circ}$. The importance of low energy neutrons $(\sim 1 \mathrm{keV})$ varies less with toroidal angle.

Figures 9 show $I_{\mathrm{a}}(E, \phi, \eta)$ for $2 \mathrm{MeV} \leq \mathrm{E} \leq 3 \mathrm{MeV}$, for $\phi=0,30,60,90$ degrees (in arbitrary units). The neutrons emitted in directions toward the detector are clearly more likely to contribute to the response than those emitted in directions awny from the detector. Consequently, it is most important to model the bays in the neighborhood of the detector correclly in order to calculate the delection efficiency accurately.

\section{Summary and Future Work}

We have carried out extensive nentron transport studies for the response of the ${ }^{335} \mathrm{U}$ fissiun detectors on the I'l'T'R. The model developed has been shown to produce results in reasonably good agreement with those of the in-situ experiments. We then extrended the numerical simulations to derive the ${ }^{235} \mathrm{U}$ detector efficiencies for the plasma UD neution source, and to explore the detector sensitivities to various sourcedetectur configurations for which the experimental results are difficult to obtain. The derived detector efficiency ratios of $\mathrm{DD}$ to ${ }^{252} \mathrm{Cf}$ neutrons for the two ${ }^{235} \mathrm{U}$ fission detectors, NE-1 and NE-2, are 1.10 and 1.08 , respectively, with $\pm 7 \%$ uncertainty due to the statistical sampling. These values have been used ju the assessment of t)e overaí lission detector elliciencies for the December 1988 in-situ calibration, and will be used in the future fusion yield measurement on the TFTR.

T'he $7 \%$ uncertainty mentioned above is still quite large, when compared to other uncertainties in the deternination of DD fusion yields on the TFTR, such as the emission prolile effects, counter dead time and stability. On the average, it took several hundred ininutes of Cray-2 time to obtain a solution will $\leq 5 \%$ statistical error for a toroidal source. 'Thus, it is impractical to further reduce the calculational uncertainty unless much more effort is devoted to improve the Monte Carlo sampling. One way to achieve this is to better understand the importance of neution scattering in various regions. While we have carried ont a study to identify the importance function of the neutron initial energy, toroidal location, and polar angle of emission, we have not altempted to extend the same work to the scattering regions. Another area which we have not tried to quantify in detail is the effect of changing the material distributions as might happen in the future. We have seen, however, that, although the material distributions are quite different in bay $\mathrm{C}$ and $\mathrm{M}$, the two ${ }^{235} \mathrm{U}$ detectoi efficiencies differ by only $\sim 5-10 \%$. In our previous study, we have also observed 
that the detector response is relatively insensitive to minor changes in the density factors in the two homogenizes malerial zones. Nonetheless, with the expectation of further machine modificative and installation of diagnostics, it would be useful to carry out more studies to better quantify any additional uncertainties in the presently evaluated efficiencies. Finally, the cross section sensitivity, in particular the effect of transferring the source energy from ${ }^{252} \mathrm{Cf}$ where the mode! has been calibrated with experiments, to the DD or DT fusion neutrons, needs to be studied.

We have not yet attempted to simulate the detector responses for other neutron detection systems, such as the ${ }^{230} \mathrm{U}$ fission chambers and the proton-recoil counter on the 'I'FT'R, which have different response cliaracteristics. Some moderate effort lias been made to use the presently calibraied model to simulate the foil activation rcsponzes. The calculated rcaction ratcs for the $\mathrm{ln}, \mathrm{Al}$, and $\mathrm{Cu}$ foils are within $30 \%$ of the experimental evaluations. ${ }^{12}$ The reliability of the curient model and the calculational approach can be furcher verified, and a letter nuterstanding of the ncutrun transport in the TF'l'R geometry can be obtained by the sinulation of these detector responses.

\section{Acknowledgements}

The atthors wish to acknowledge the efforts by the TFTR Fusion Product Diagnostic Group, particularly in connection with the calibration experiments. The authors are also indebted to the support and encouragement of Dr. K. M. Young. This work was supported by US DoE Contract DE-AC02-76-CHO-3073. 


\section{References}

'J. D. Strachan et. al., "High-Tersperature Plasmas in the Tokamak Fusion Test Reactor," Phys. Rev. Lett. $\underline{58}, 1004$ (1987).

${ }^{2} H$. W. IIendel, A. C. England, D. L. Jassby, A. A. Mirin, and E. B. Nieschmidt, "Fusion-Neutron P'roduction in the TFTR with Deuterium Neutral Beam Injec(ivin," J. Fus. Energy ㅁ, 231 (1986).

${ }^{3} \mathrm{H}$. W. Hendel et al., "In-Situ Calibration of TFTR Neutron Detectors," Rev. Sci. Instrum. (To be published). Also in the Proceedings of International Workshop on Nentrun Calibration in Tukanaks, Princelun Plasma Physics Laboratory, 1-3 August (1989).

${ }^{4}$ L.P. Ku, II. W. Fendel, and S. L. Ijiew, "Calculation of the Absolute Detections l'filiciency of a Moderated ${ }^{235} \mathrm{U}$ Neutron Inetector on the 'Tokannok Fusion 'Fest Reactor," Nucl. Instrum. Method $\underline{\text { A280, }} 113$ (1989).

${ }^{5}$ Gamma-Metrics Inc., San Diego, CA, USA.

"Los Alamos Monte Carlo Group, "MCNP-A General Monte Carlo Code for Neutron and Photon Transport Version 3A," LANL Report LA-7396-M, Rev. 2(1986).

'B. A. Alagurno and P. G. Young, Editors, "ENDF-201 Supplement I, ENDF/B-V.2 Sumunary Documentation," Brookhaven National Laboratory Report BNL-NCS$17541(1985)$.

J. A. Grundl and C. M. Eisenhauer, "Fission Spectrum Neutrons for Cross Section Validation and Neutrou Flux 'Transfer," NBS Special Publicalion 425, 250 (1975).

${ }^{9}$ II. W. Lendel, D. L. Jassby, H. S. Bosch, C. W. Barnes, L. C. Johnson, T. J. Murphy, E. B. Niescludidt, T. Saito, J. D. Straclian, G. D. Tait, and K. M. Young, "TFTR Epitliermal Neutron Detector System: Recalibration and Effect of Nunisotropic Neutron Enission," Rev. Sci. Instrum. $\underline{59}$ (8), 1682 (1988).

${ }^{10 H}$ H. Liskien, and A. Paulsen, "Neutron Production Cross Sections and Energies for the Reactions $\mathrm{T}(\mathrm{p}, \mathrm{n})^{3} \mathrm{He}, \mathrm{D}(\mathrm{d}, \mathrm{n})^{3} \mathrm{He}$, and $\mathrm{T}(\mathrm{d}, \mathrm{n})^{4} \mathrm{He}$," Nucl. Data Tables $\underline{\mathbb{L}}, 569$ (1973).

"E. B. Nieschmid, A. L. England, H. W. Ilendel, D. L. Hills, J. A. Issacson, L. P. Ku, and F. Y. Tsang, "Effects of Neutron Energy Spectrum on the Efficiency Calibralion of Epithermal Neutron Detectors," Rev. Sci. Instrum. 56, 1084 (1985). 
${ }^{12}$ L. P. Ku, "Numerical Simulations of Neutron Detector Calibration Experiments on the Tukamak Fusion Test Reactor," Presented at International Workshop on Neutron Calibration in Tokamaks, Princeton Plasma Physics Laboratory, 1-3 August (1989). 


\begin{tabular}{|c|c|c|c|}
\hline Delector & Fissile Mat & Mass & Source Range $(n / s)$ \\
\hline & & & \\
NE-1 & $\mathrm{U}-235$ & 1.3 & $1 \cdot 10^{12}-1 \cdot 10^{17}$ \\
NE-2 & $\mathrm{U}-235$ & 1.3 & $1 \cdot 10^{12}-1 \cdot 10^{17}$ \\
NE-3 & $\mathrm{U}-238$ & 1.3 & $1 \cdot 10^{16}-1 \cdot 10^{21}$ \\
NE-4 & $\mathrm{U}-238$ & 1.3 & $1 \cdot 10^{10}-1 \cdot 10^{21}$ \\
NE-5 & $\mathrm{U}-238$ & 44.0 & $5 \cdot 10^{13}-5 \cdot 10^{18}$ \\
NE-6 & $\mathrm{U}-235$ & 18.0 & $5 \cdot 10^{10}-2 \cdot 10^{13}$ \\
NE-7 & $\mathrm{U}-238$ & 44.0 & $5 \cdot 10^{13}-5 \cdot 10^{10}$ \\
\hline
\end{tabular}

Table 1: Fission detectors in TFTR

\begin{tabular}{|c|c|c|c|}
\hline \multirow[t]{2}{*}{ Delector } & \multirow{2}{*}{$\begin{array}{c}\text { Toroidal } \\
\text { Angle }\end{array}$} & \multicolumn{2}{|c|}{ Delection Efficiency $(c / n)$} \\
\hline & & Calculated & Measured \\
\hline NE-1 & $0^{\circ}$ & $\begin{array}{c}1.27 \cdot 10^{-8} \pm 2.6 \% \dagger \\
1.30 \cdot 10^{-8} \pm 2.7 \%\end{array}$ & $1 . \overline{27} \cdot \overline{10^{-8}} \pm 2.3 \%$ \\
\hline $\mathrm{NE}-\mathrm{I}$ & $30^{\circ}$ & $7.10 \cdot 10^{-9} \pm 6.0 \%$ & $6.91 \cdot 10^{-9} \pm 4.3 \%$ \\
\hline NE-I & $45^{\circ}$ & $4.85 \cdot 10^{-9} \pm 8.6 \%$ & $4.10 \cdot 10^{-9} \pm 7.9 \%$ \\
\hline$N \bar{E}-1$ & all & $3.15 \cdot 10^{-9} \pm 5.0 \%$ & $3 . \overline{00} \cdot 1 \overline{0}^{-\overline{8}} \pm 3.0 \overline{\%}$ \\
\hline NE-2 & $0^{\circ}$ & $\begin{array}{l}1.15 \cdot 10^{-8} \pm 3.0 \% \dagger \\
1.23 \cdot 10^{-6} \pm 3.3 \%\end{array}$ & $1.21 \cdot 10^{-8} \pm 3.0 \%$ \\
\hline NE-2 & all & $2.92 \cdot 10^{-9} \pm 5.0 \%$ & $2.96 \cdot 10^{-9} \pm 3.0 \%$ \\
\hline
\end{tabular}

Talole 2: Comparison of detection efficiencies for ${ }^{235} \mathrm{U}$ detectors between calculation and measurement. $f A$ crylic source holder included in the simulation. 


\begin{tabular}{|c|c|c|c|c|}
\hline \multicolumn{2}{|c|}{ Source Position } & Distance to & \multicolumn{2}{|c|}{ Efficiency $(\mathrm{c} / \mathrm{n})$} \\
$\mathrm{R}(\mathrm{m})$ & $\mathrm{z}(\mathrm{m})$ & Detector $(\mathrm{m})$ & TF modeled & TF not modeled \\
\hline 3.164 & -0.30 & 2.83 & $1.72 \cdot 10^{-6} \pm 3.6 \%$ & $3.08 \cdot 10^{-6} \pm 4.2 \%$ \\
\hline 2.907 & -0.15 & 3.12 & $1.45 \cdot 10^{-8} \pm 4.1 \%$ & \\
\hline 2.650 & 0.00 & 3.42 & $1.23 \cdot 10^{-8} \pm 3.3 \%$ & $2.32 \cdot 10^{-6} \pm 4.3 \%$ \\
\hline 2.393 & 0.15 & 3.72 & $1.05 \cdot 10^{-8} \pm 4.8 \%$ & \\
\hline 2.136 & 0.30 & 4.02 & $8.55 \cdot 10^{-6} \pm 4.6 \%$ & $1.86 \cdot 10^{-6} \pm 4.5 \%$ \\
\hline
\end{tabular}

Table 3: Calculated NE-2 efficiencies for source locations along the line-of-sight

\begin{tabular}{|l|l|c|c|}
\hline Energy & ${ }^{252} \mathrm{Ct}$ & With l'olyethylene & Wilh SS-316 \\
\hline$<10 \mathrm{keV}$ & 0.0003 & 0.171 & 0.014 \\
\hline $101-130 \mathrm{keV}$ & 0.010 & 0.055 & 0.027 \\
\hline $1010-500 \mathrm{keV}$ & 0.094 & 0.110 & 0.148 \\
\hline $500-800 \mathrm{keV}$ & 0.087 & 0.068 & 0.123 \\
\hline $0.8-1.0 \mathrm{MeV}$ & 0.061 & 0.044 & 0.077 \\
\hline $1.0-2.0 \mathrm{MeV}$ & 0.272 & 0.199 & 0.278 \\
\hline $2.0-3.0 \mathrm{MeV}$ & 0.198 & 0.137 & 0.146 \\
\hline $3.0-5.0 \mathrm{MeV}$ & 0.193 & 0.141 & 0.129 \\
\hline $5.0-10.0 \mathrm{MeV}$ & 0.081 & 0.071 & 0.055 \\
\hline
\end{tabular}

'Table f: Fraction of neutrons emitted in various energy bins for different source shijelds at $90^{\circ}$ emission angle 


\begin{tabular}{|c|c|}
\hline Source Condition & Detection Efficiency $(\mathrm{c} / \mathrm{n})$ \\
\hline bare, isotropic, $0^{\circ}$ & $1.23 \cdot 10^{-8} \pm 3 \%$ \\
\hline with polyethylene shield, $0^{\circ}$ & $7.65 \cdot 10^{-9} \pm 5 \%$ \\
\hline with SS-316 shield, $0^{\circ}$ & $9.75 \cdot 10^{-9} \pm 6 \%$ \\
\hline $\begin{array}{l}\text { bare, with angular distribution } \\
\text { from polyethylene shield, } 0^{\circ}\end{array}$ & $1.04 \cdot 10^{-3} \pm 6 \%$ \\
\hline $\begin{array}{l}\text { bare, with } \mathrm{DD} \text { neutron angular } \\
\text { distribution, } 0^{\circ}\end{array}$ & $1.10 \cdot 10^{-8} \pm 5 \%$ \\
\hline bare, isolropic, $30^{\circ}$ & $6.84 \cdot 10^{-9} \pm 4 \%$ \\
\hline with SS-3!6 shield, 31/0 & $6.81 \cdot 11^{-6} \pm 4 \%$ \\
\hline $\begin{array}{l}\text { luare, with DD neutron angular } \\
\text { distributicn, } 30^{\circ}\end{array}$ & $8.10 \cdot 10^{-9} \pm 5 \%$ \\
\hline
\end{tabular}

Tiahle 5: Calculated NE-2 efficiencies with various source binsing

\begin{tabular}{|c|c|c|}
\hline Detector & Source Condjition & Efficiency $(\mathrm{c} / \mathrm{n})$ \\
\hline $\mathrm{NE}-1$ & $\mathrm{k} T=5 \mathrm{keV}$ & $3.55 \cdot 10^{-9} \pm 5.0 \%$ \\
\hline $\mathrm{NE}-1$ & $\mathrm{kT}=25 \mathrm{keV}$ & $3.48 \cdot 10^{-8} \pm 4.8 \%$ \\
\hline $\mathrm{NE}-1$ & $120 \mathrm{keV} \mathrm{J} \rightarrow \mathrm{D}$ & $3.66 \cdot 10^{-9} \pm 4.8 \%$ \\
\hline $\mathrm{NE}-2$ & $\mathrm{kT}=25 \mathrm{keV}$ & $3.15 \cdot 10^{-8} \pm 5.0 \%$ \\
\hline $\mathrm{N} E-2$ & $120 \mathrm{keV} \mathrm{D} \rightarrow \mathrm{D}$ & $3.40 \cdot 10^{-8} \pm 4.5 \%$ \\
\hline
\end{tabular}

Table 6: Calculated ${ }^{235} \mathrm{U}$ delector efficiencies for DD neutrons 


\section{Figure Captions}

Fig. 1 Neutron source strength during a neutral-beam injection shot measured by NE-2.

Fig. 2 Calculated relative surface efficiency (normalized at $11 \mathrm{MeV}$ ) of ${ }^{235} \mathrm{U}$ detector/moderator assembly as function of neutron energy.

Fig. 3 Fission neutron spectrum as function of energy.

Fig. 4 Dxamples slinwing the three-rlimensional MCNP model of the TFTR for the Munte Carlo calculations. (a) Plane and elevation views of bay C. (b) Plane and elevation views of bay $M$.

Fig. 5 'lypical count rate versus toroidal angle measured by $N E-2$ with a ${ }^{252}$ C.f sularce.

Fig. 6 Distriluntions of polar angle of emission. The solid line is the distribution due to unidirectional $120-k e V ~ D \rightarrow D$. The dots represent the distribution due to balanced co- and counter-injection of $12 \mathrm{U}-\mathrm{keV} \mathrm{D} \rightarrow \mathrm{D}$. The long dashed line is the alistribution expected from the polyethylene shadow shield surrounding the ${ }^{252}$ Cf sontrce. The short dashed line is the distribution expected from the SS316 shadow shield surrounding the ${ }^{252} \mathrm{Cf}$. All the distributions are normalized to the emission probability at $\mathbf{u}^{\circ}$.

Fig. 7 Calculated detection elticiency of NE-2 versus major radjus of neutron emissinn for ring sources. The discrete data with error bars are $\pm 1 \sigma$ results of Monte Carlo calculation. The straightline is the result of linear least square fit.

Fig. 8 Relative importance of neutron initial energy in contributing to NE-2 response for source toroidal angles $\phi=0^{\circ}, 30^{\circ}, 60^{\circ}, 90^{\circ}, 120^{\circ}, 150^{\circ}$, and $180^{\circ}$ (in decreasing magnitude).

Fig. 9 Relative importance of initial polar angle of emission in contributing to NE-2 response for source toroidal angles (a) $\phi=0^{\circ}$, (b) $\phi=30^{\circ}$, (c) $\phi=60^{\circ}$, and (d) $\phi=90^{\circ}$. 
\#89X0325

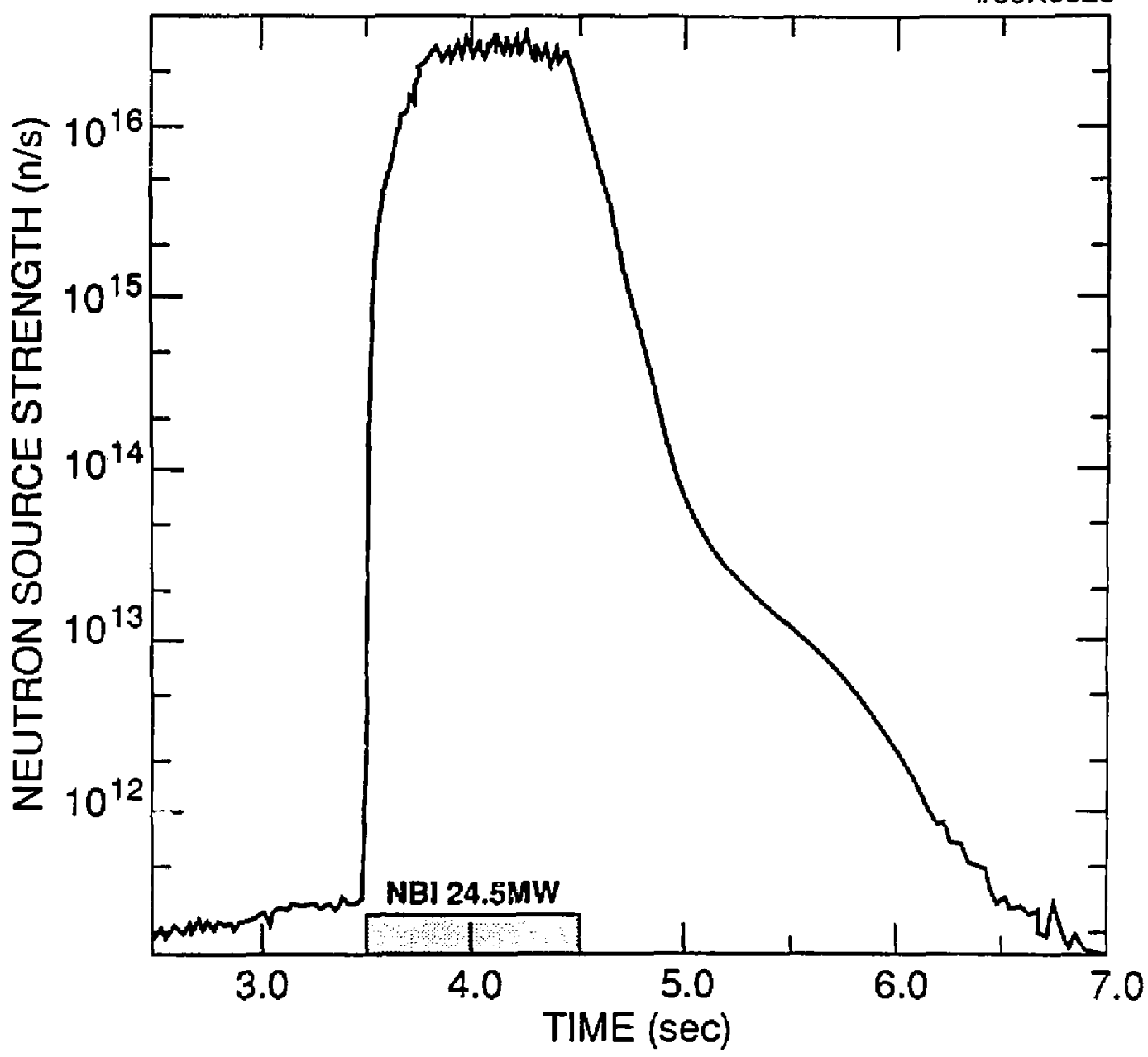

FIG. 1 


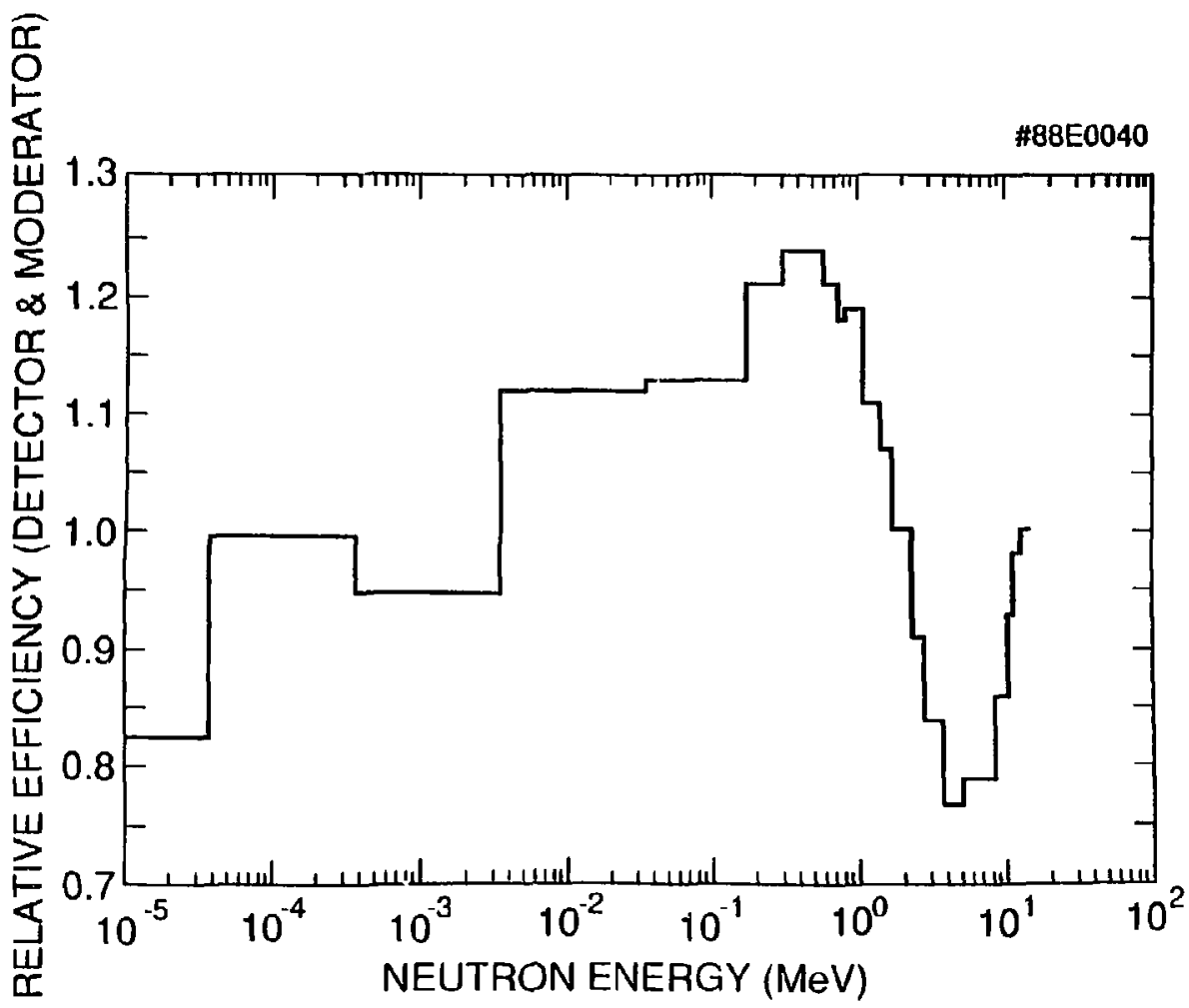

liki, ? 


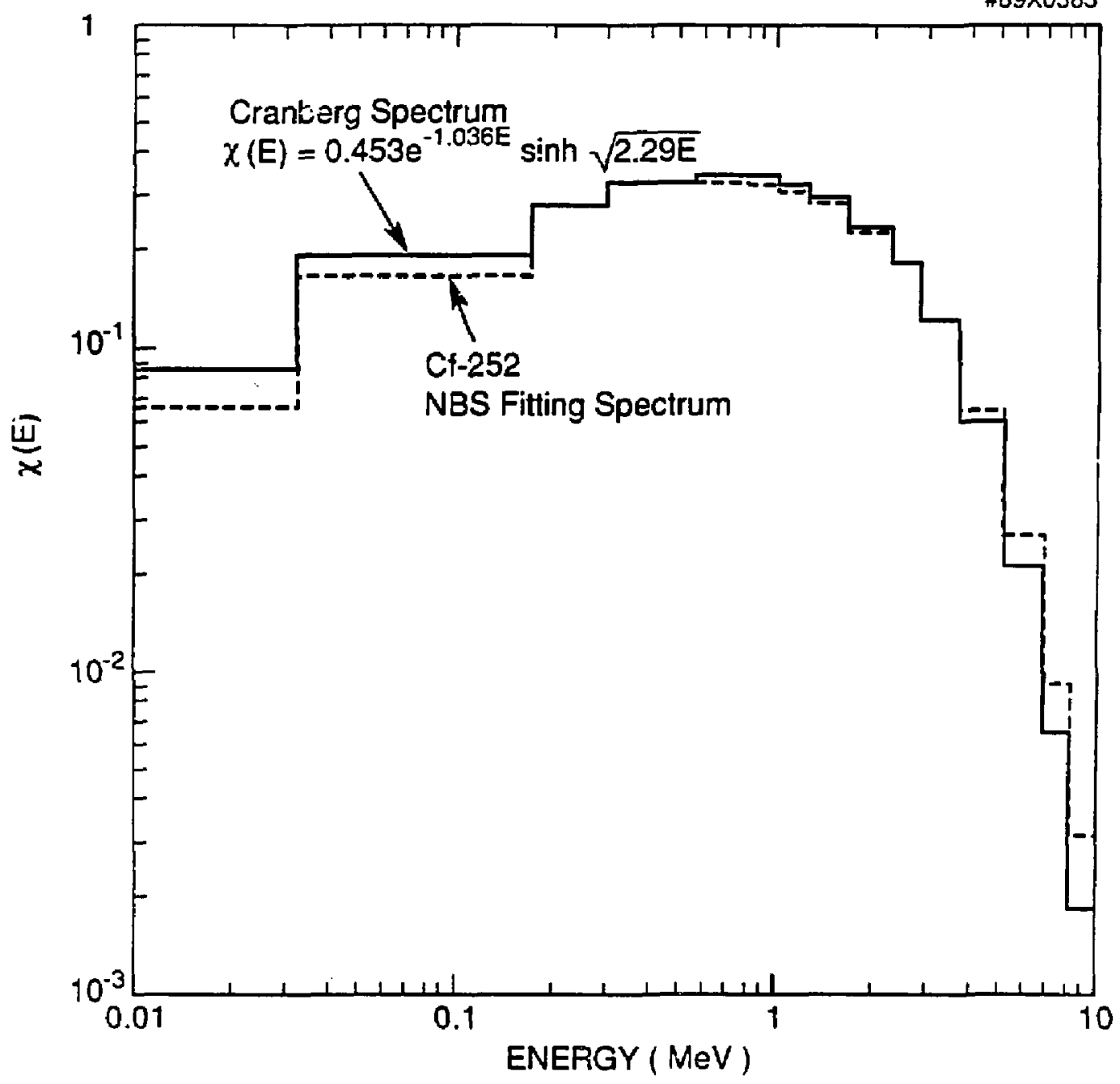

FIG. 3 


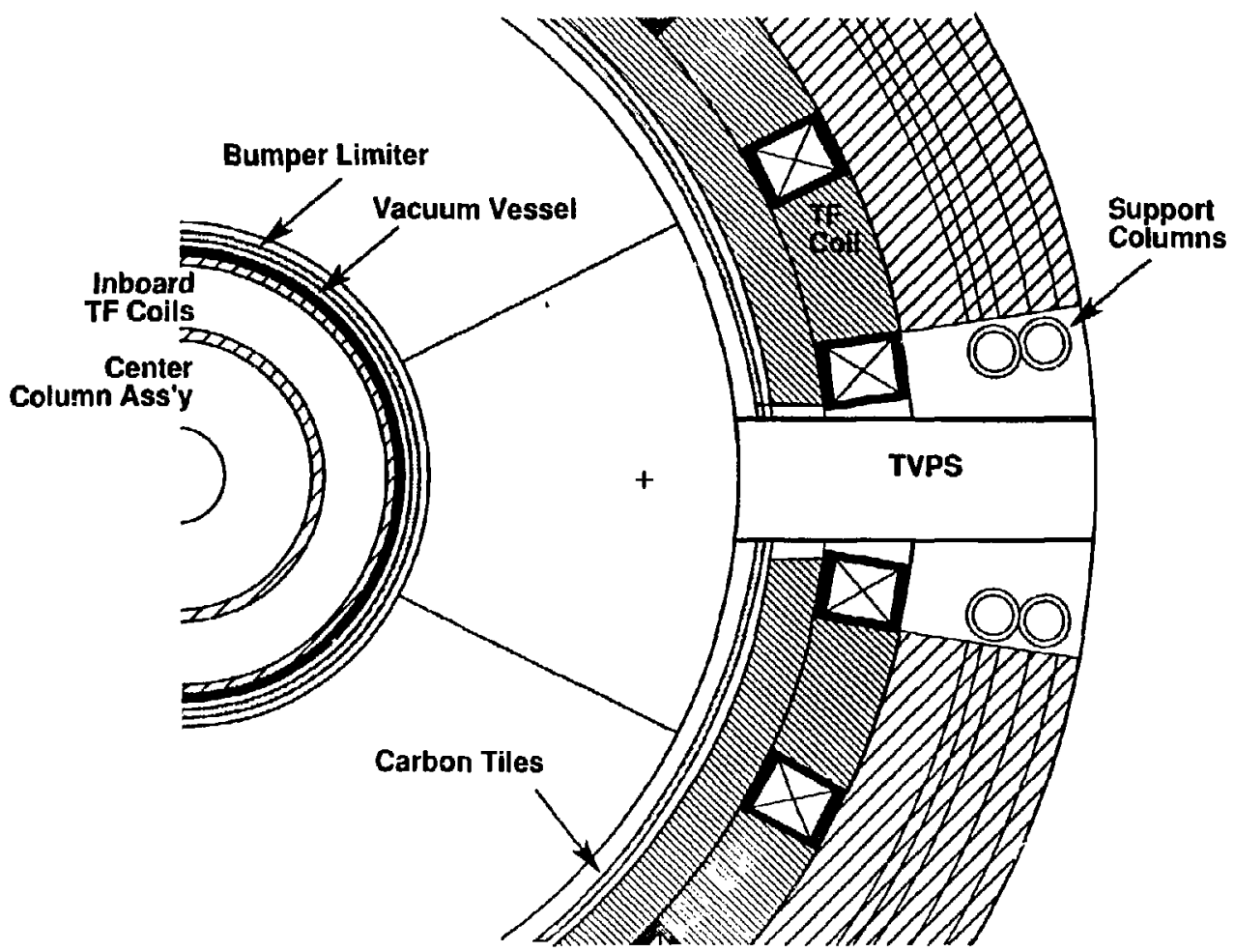

Hif. hal(1) 


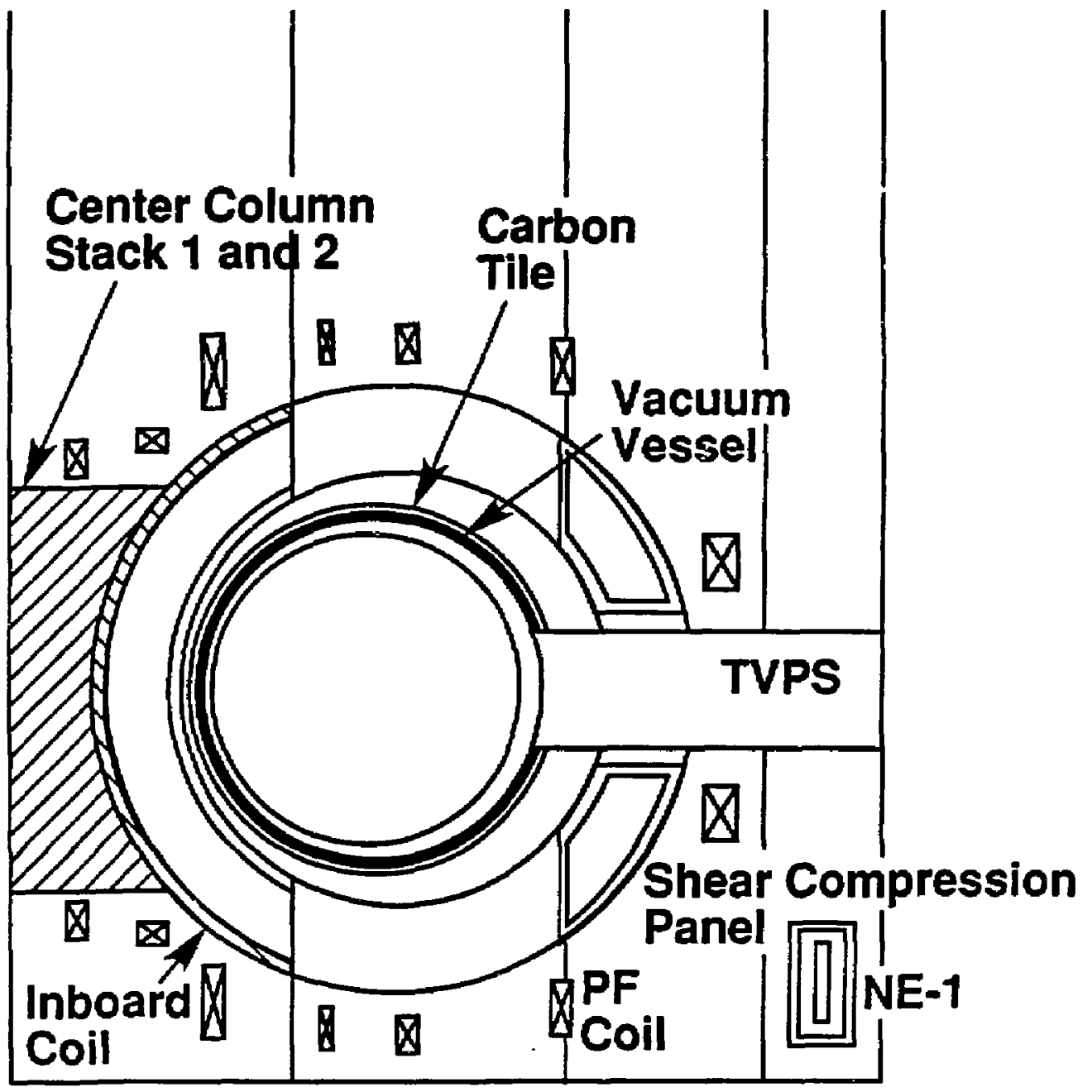

FIG. $4 a(2)$ 


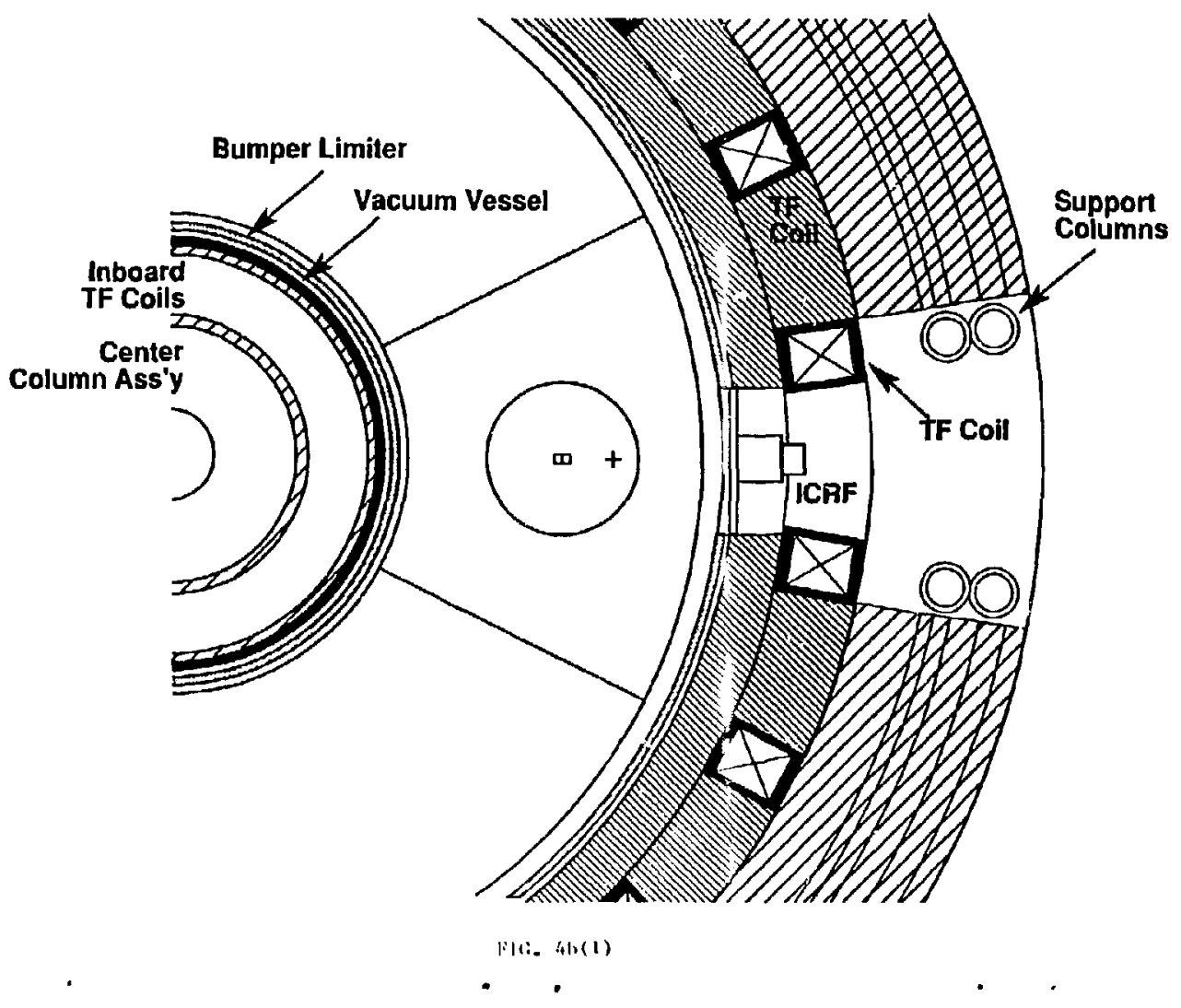




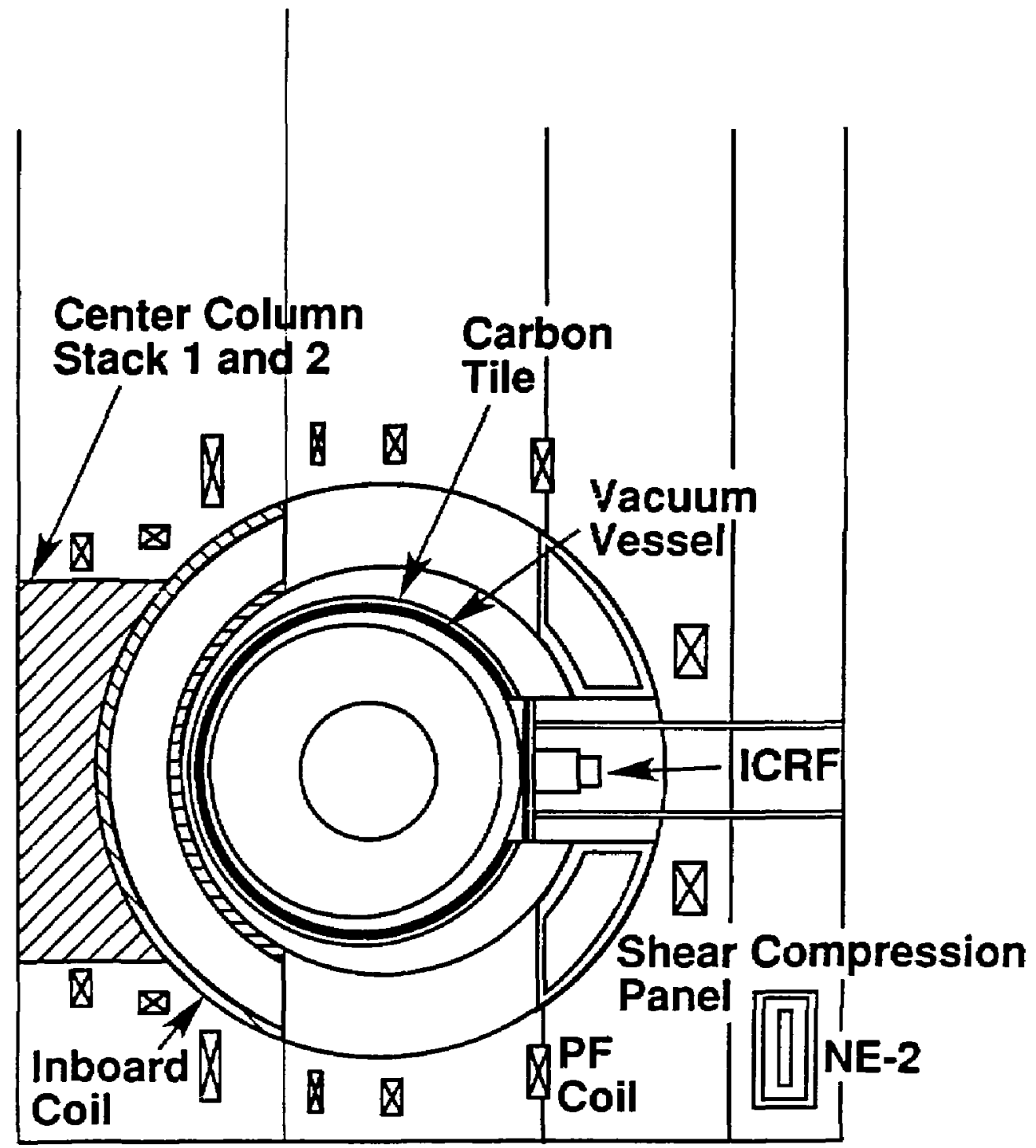

FIG. $4 b(2)$ 


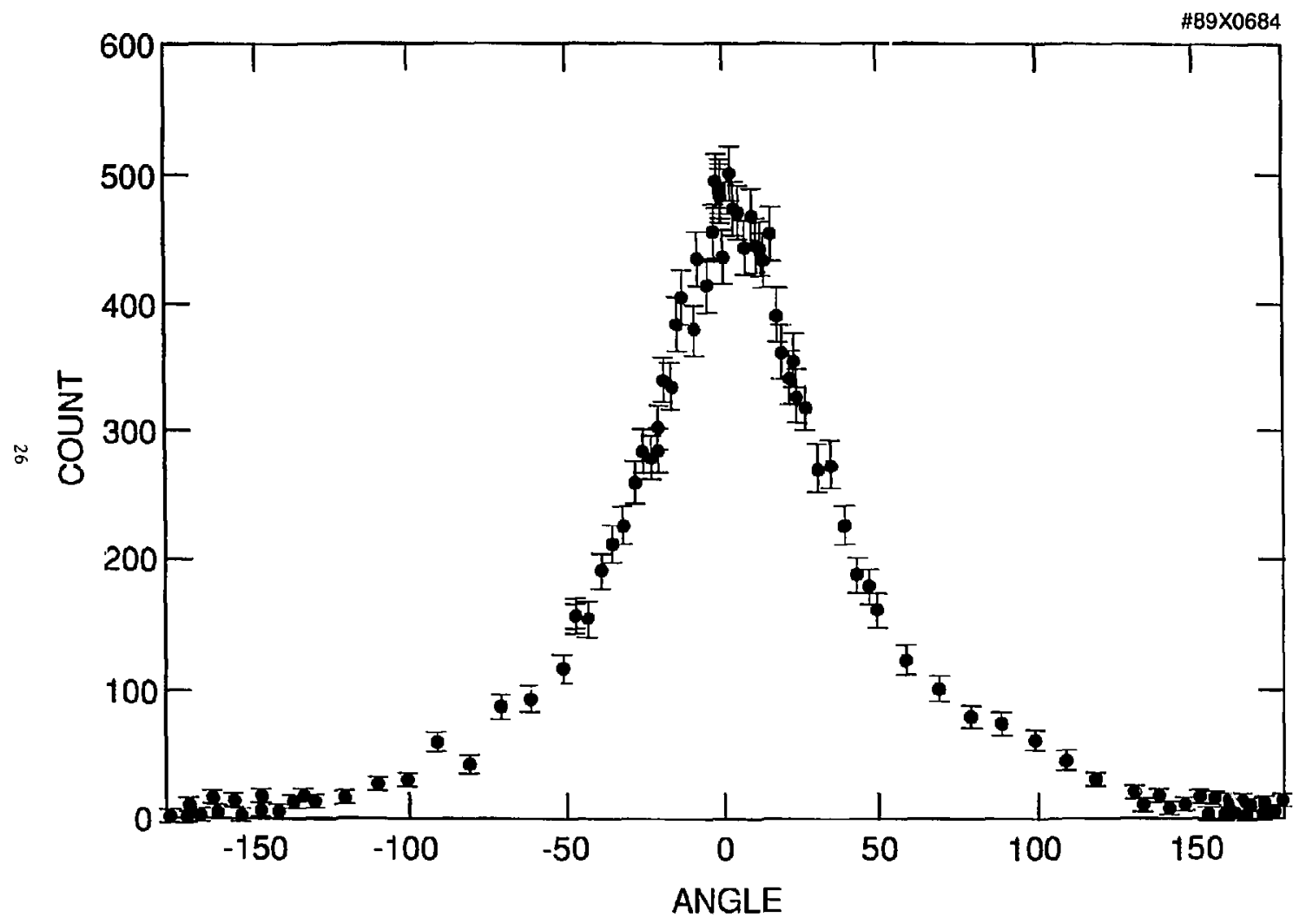




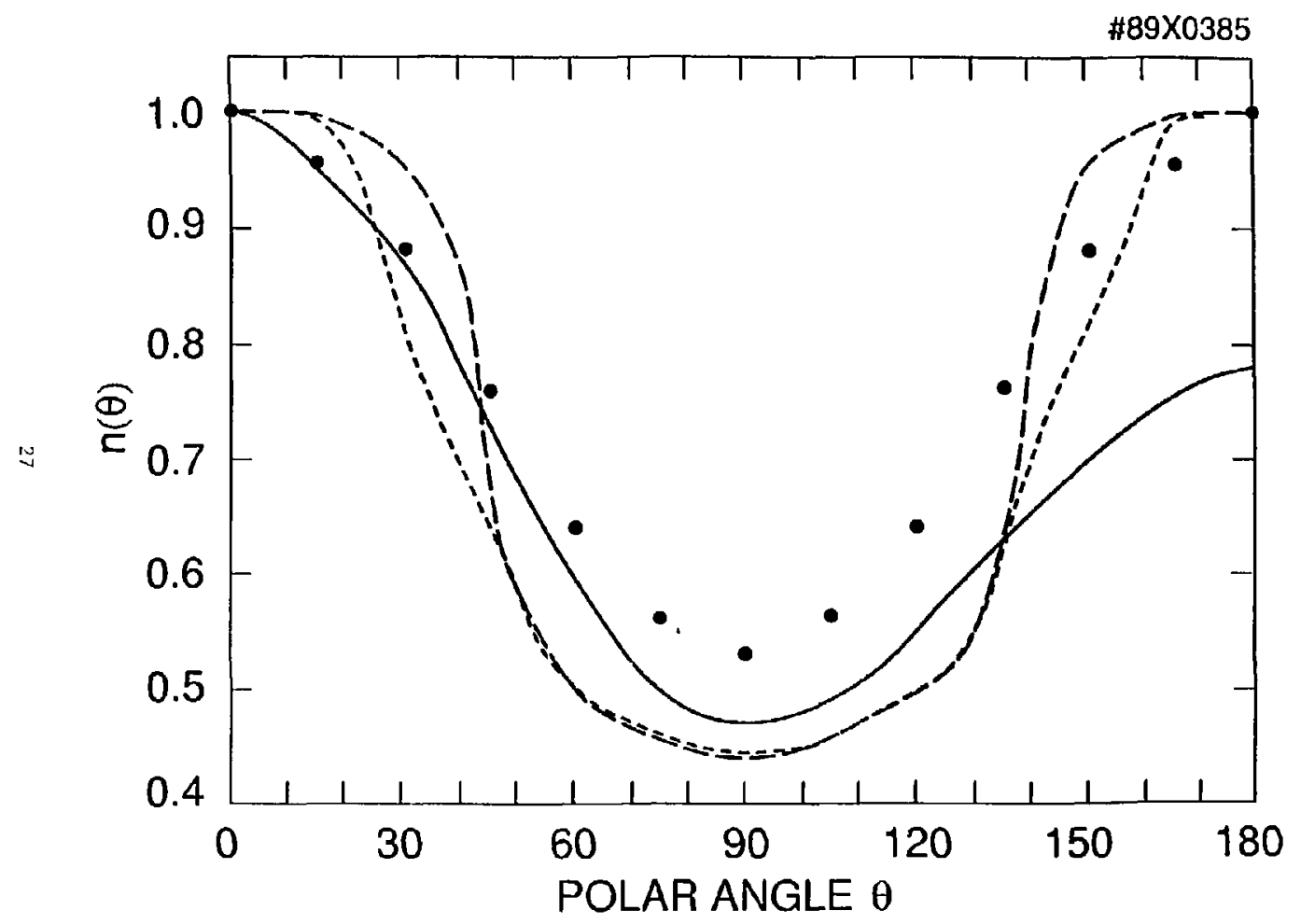

lifi. 6 


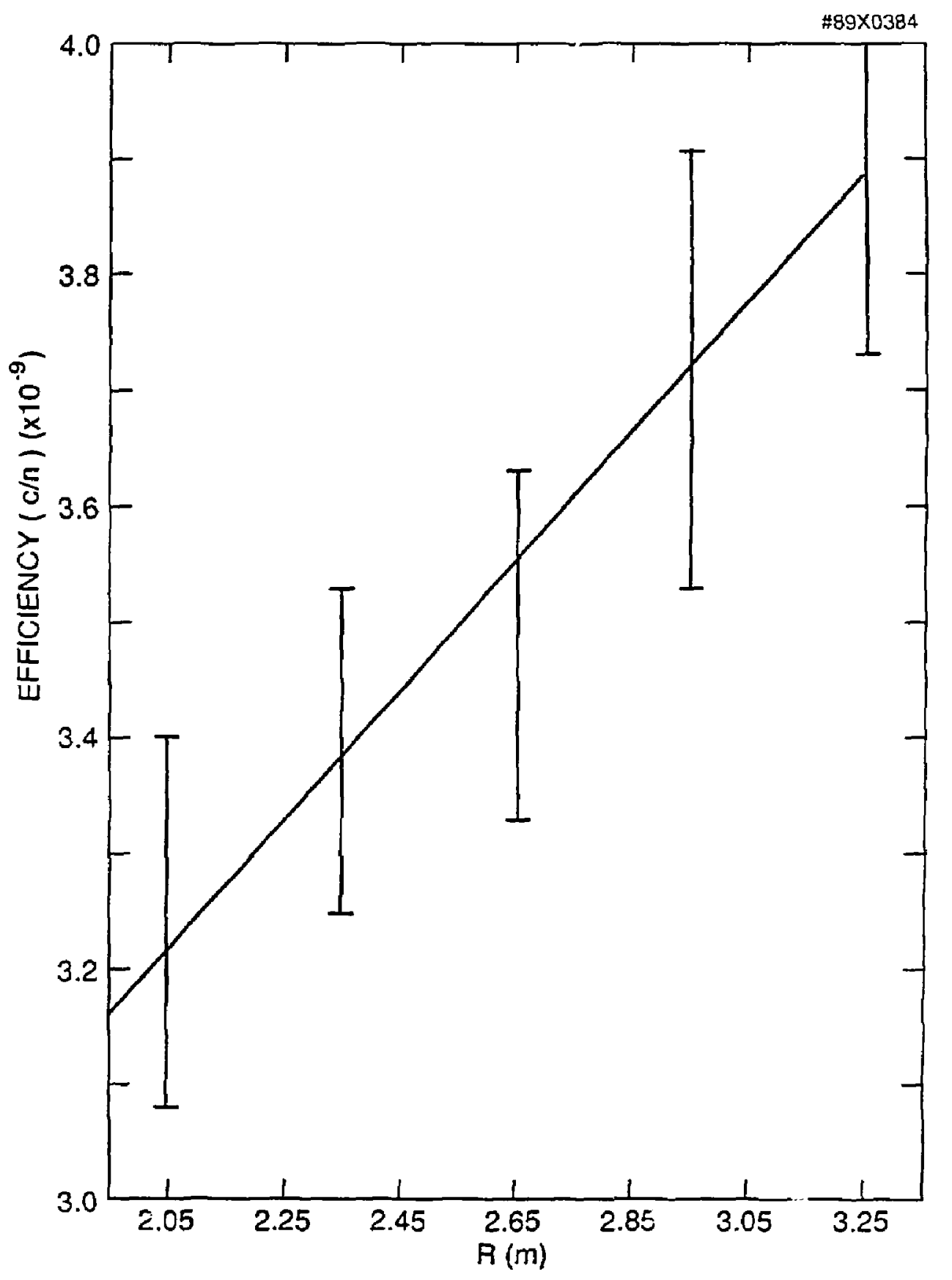

FIG. 7 


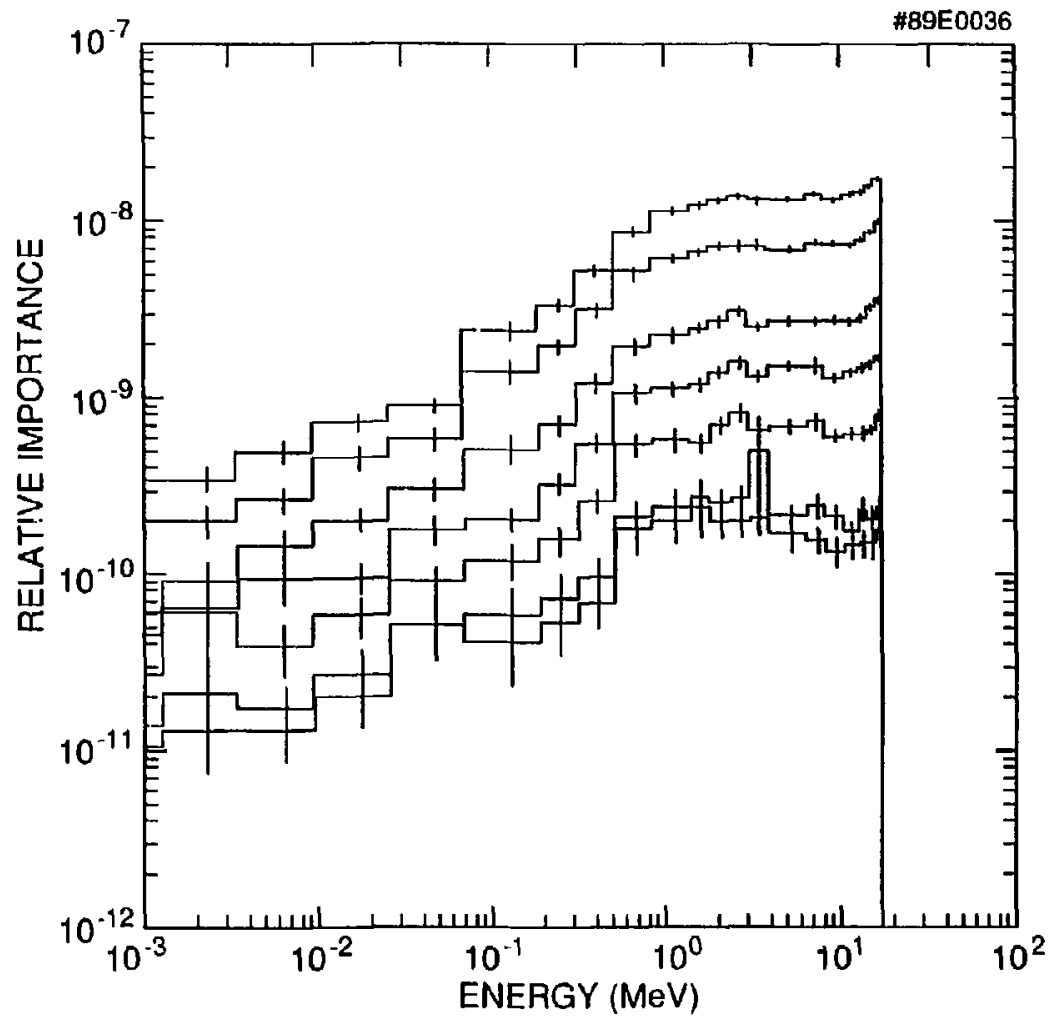




\section{RELATIVE IMPORTANCE}

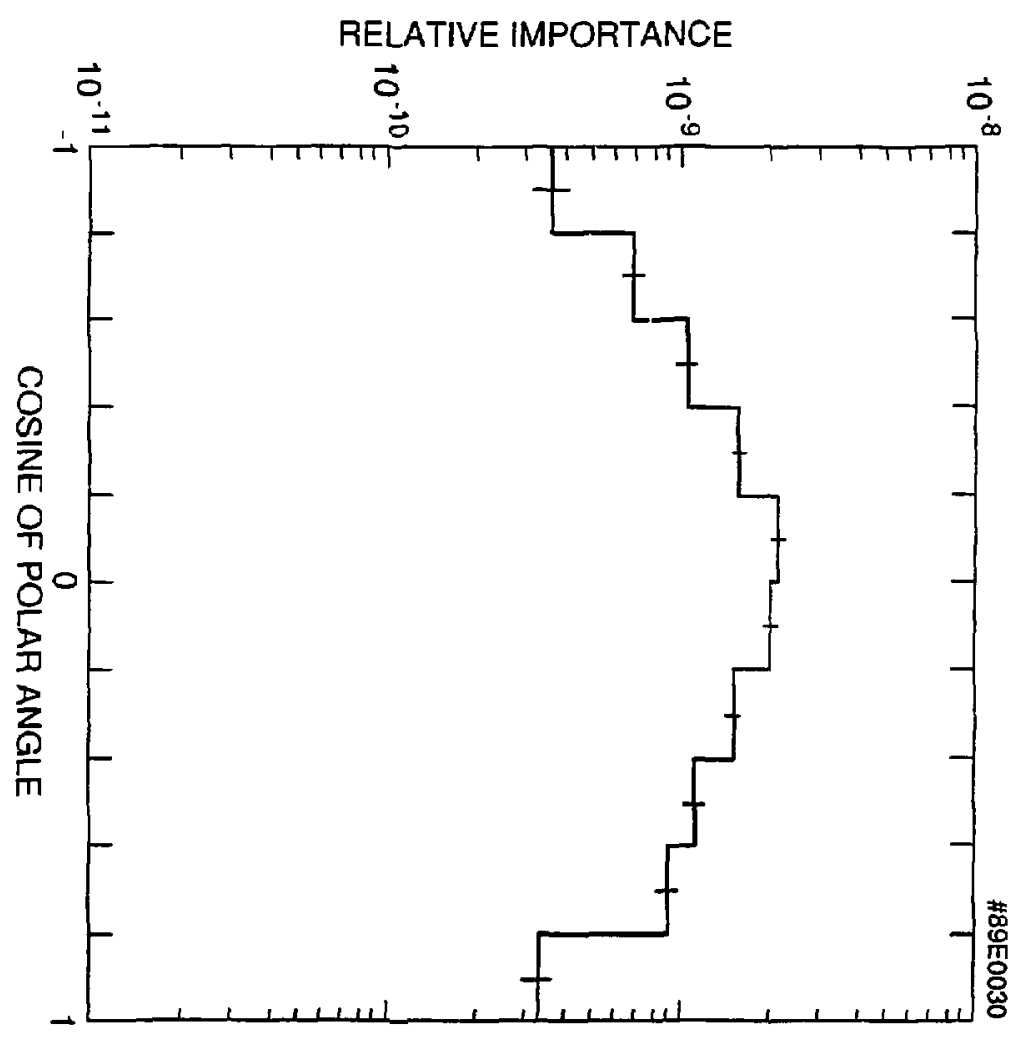


RELATIVE IMPORTANCE

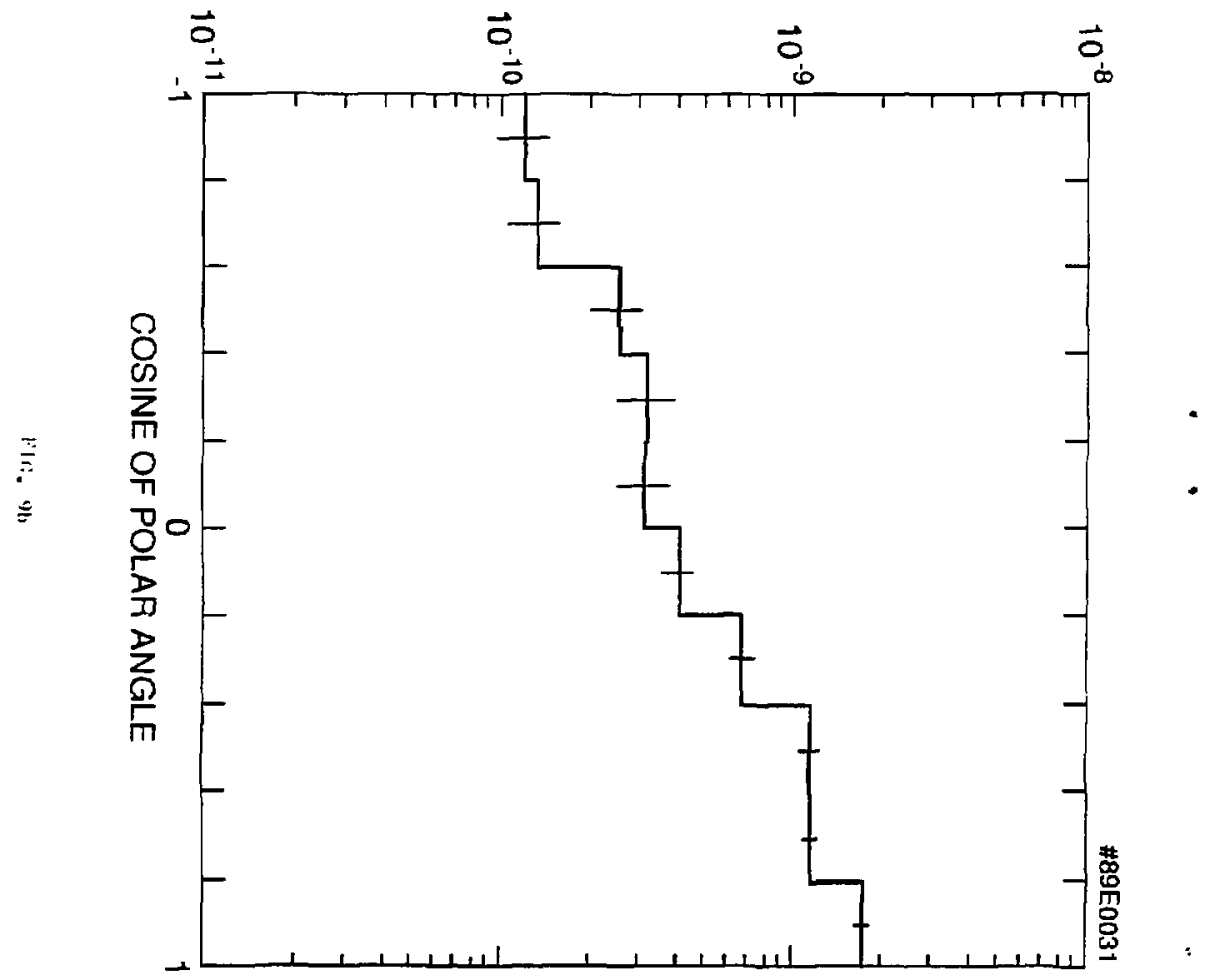




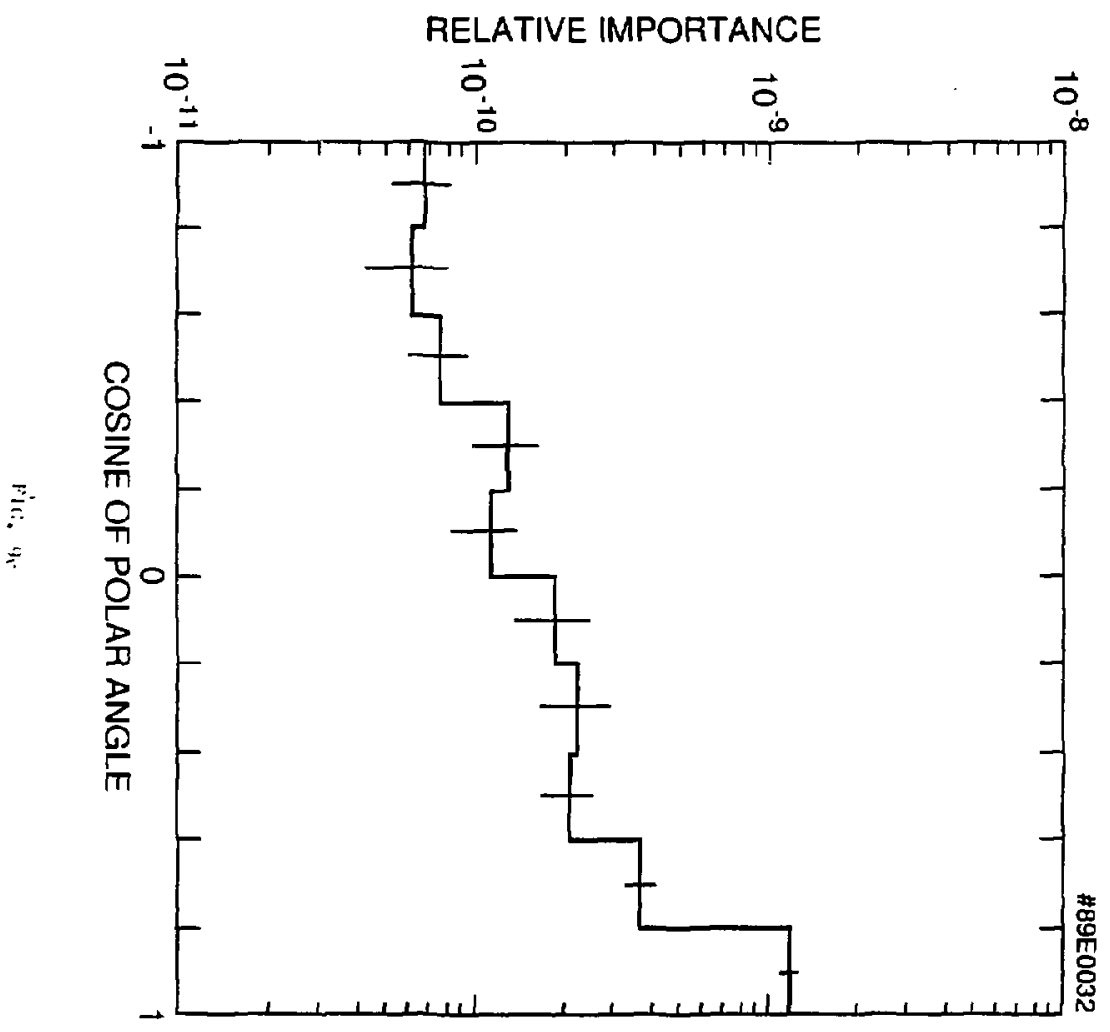


RELATIVE IMPORTANCE

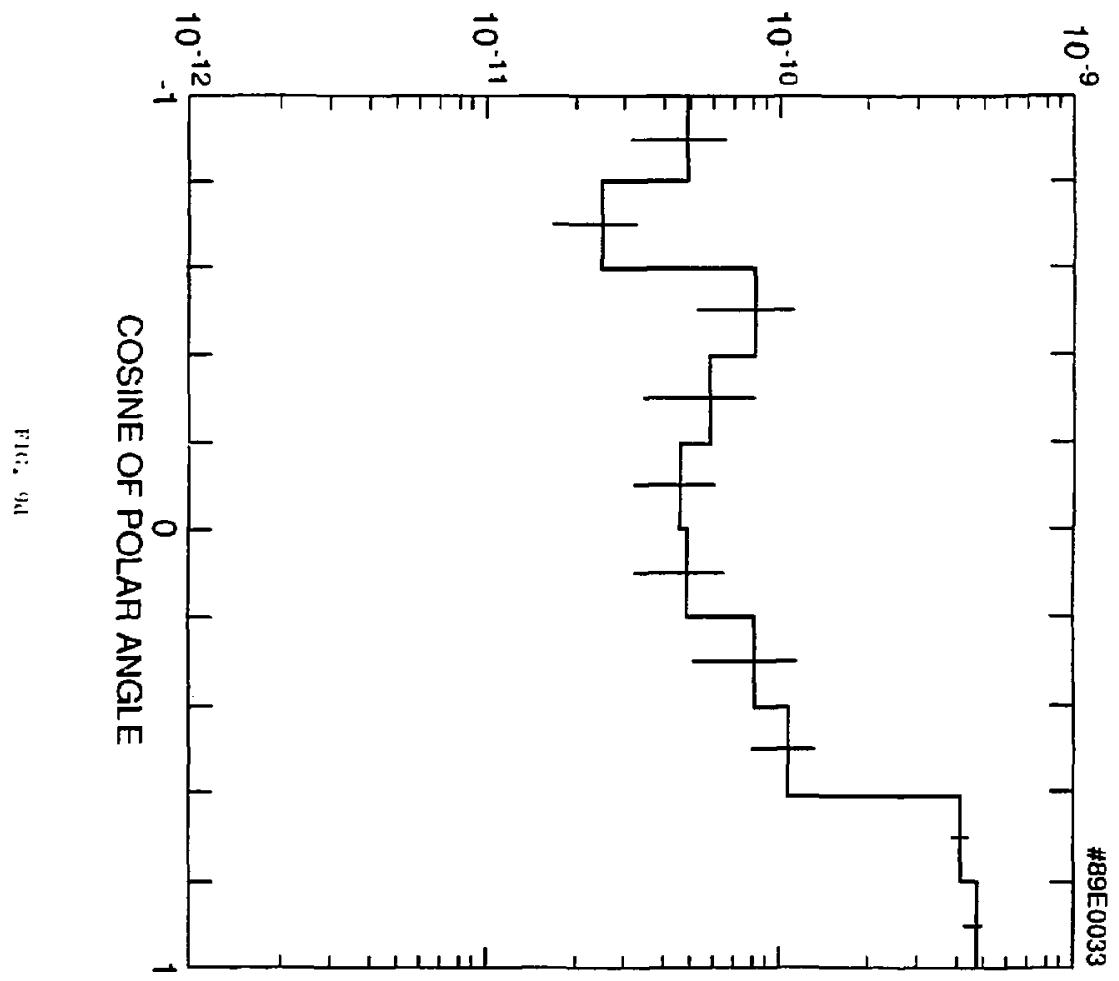

